\title{
Turismo rural en el distrito de Chacas, departamento de Ancash, Perú
}

\section{Rural tourism in the district of Chacas, Department of Ancash, Peru}

\author{
Luis Guillermo Sicheri Monteverde \\ Fernando Alexis Nolazco Labajos \\ Silvia Francisca Malvas Silvestre \\ Universidad Norbert Wiener, Perú
}

Autor para correspondencia: luis.sicheri@uwiener.edu.pe; fernandonolazco@gmail.com

Fecha de recepción: 3 de febrero del 2019 - Fecha de aceptación: 15 de abril del 2019

Resumen: La investigación se realizó en Chacas - Ancash, dirigido a la comunidad y especialistas en el sector turístico. El objetivo fue diseñar un plan de potencialización del turismo rural en el distrito de Chacas, departamento de Ancash, Perú, para lo cual se tuvo que realizar un diagnóstico con el apoyo de las encuestas y entrevistas. El estudio se trabajó con el enfoque mixto, sintagma holístico, de tipo proyectiva, abordando en un plan a partir de las debilidades identificadas. La muestra estuvo constituida por cincuenta y un pobladores, y tres expertos en turismo vinculados al distrito. En los resultados destaca que los pobladores se identifican con el lugar donde habitan y participan de sus costumbres. En este sentido, las actividades de artesanía, agroturismo, caza, pesca y gastronomía están vinculadas al turismo rural. Por otra parte, hace falta mayor infraestructura para que los turistas pernocten y se alimenten, sobre todo cuando se realizan las fiestas costumbristas como es la Virgen de Asunción. Los atractivos turísticos carecen de señalización. El traslado se realiza por vía terrestre resultando ser costoso, a esto se añade la carencia de agencias de viaje que brinden servicios de manera continua. Por otra parte, destaca la existencia de varios recursos turísticos como la laguna Esmeralda, Patarcocha, Yana Raju, Laguna Belaunde, los cuales aún no se han puesto en valor. Finalmente, como alternativa de solución se planteó la implementación de trekking y hiking para el desarrollo del turismo rural, también la implementación de un portal web, fortalecimiento de la identidad cultural a través de talleres de artesanía, danza en los niños y el fomento del empleo a través de la práctica de la actividad turística.

Palabras claves: turismo rural; identidad cultural; costumbres; atractivos turísticos; recursos turísticos

Abstract: The research was conducted in Chacas - Ancash, aimed at the community and specialists in the tourism sector. The objective was to design a rural tourism potentialization plan in the district of Chacas, department of Ancash, Peru, for which a diagnosis had to be made with the support of the surveys and interviews. The study was worked with the mixed approach, a holistic syntagm, of a projective type, addressing a plan based on the identified weaknesses. The sample consisted of fifty-one residents, and three tourism experts linked to the district. In the results highlights that the villagers identify with the place where they live and participate in their customs. In this sense, the activities of crafts, agro-tourism, hunting, fishing and gastronomy are linked to rural tourism. On the other hand, there is a need for more infrastructure for tourists to spend the night and feed themselves, especially when the traditional festivities are held, such as the Virgin of Asunción. The tourist attractions lack signage. The transfer is made by land, which is costly, to which is added the lack of travel agencies that provide services on an ongoing basis. On the other hand, it highlights the existence of several tourist resources such as the Esmeralda lagoon, Patarcocha, Yana Raju, Belaunde lagoon, which have not yet been put into value. Finally, as an alternative solution, the implementation of trekking and hiking was proposed for the development of rural tourism, as well as the 
implementation of a web portal, strengthening of cultural identity through craft workshops, dance in children and the promotion of employment through the practice of tourist activity.

Keywords: rural tourism; cultural identity; customs; tourist attractions; tourist resources

\section{Introducción}

El turismo es considerado como uno de los sectores socioeconómicos más resilientes a la situación actual, representa el 10\% del PBI mundial y el $30 \%$ de las exportaciones de servicios, tiene un impacto trascendental en el desarrollo sostenible. Así también, ofrece oportunidades significativas de progreso para los pobladores de las zonas favorecidas con recursos naturales y culturales, permitiendo dinamizar la economía y crear conciencia para la conservación del patrimonio (Word Tourism Organization, 2018; Mincetur, 2018).

Una de las ramas que ha tomado mucha importancia estos últimos años es el turismo rural, cuyos orígenes se remontan en Europa con el proyecto conocido como Guites de Francia, denominando como el conjunto de acciones respetuosas del patrimonio natural e histórico, de las culturas y sociedades locales, además de ser considerado un turismo light que se practica con mucha facilidad (Forneau, 1998).

En América Latina existen países como Argentina, Chile, México, Uruguay y Colombia, que promueven el desarrollo del turismo rural con programas de apoyo a zonas rurales, entidades agropecuarias que fomentan educación, turismo, cultura y trabajo; y las "haciendas" como el caso de México que integran armoniosamente lo antiguo, moderno y rural en los alojamientos para los turistas (Organización Mundial de Turismo, 2008).

En el caso del Perú, es un país con gran biodiversidad, posee un gran potencial en recursos turísticos y la presencia de culturas vivas, aspectos importantes para el desarrollo de un turismo rural sostenible. Los departamentos con mayor notoriedad del turismo rural son Arequipa, Cuzco y Puno, y en miras a potencializar nuevos circuitos se encuentran Loreto, Amazonas y San Martín (Diario El Comercio, 2016).

Este tipo de turismo está en crecimiento significativo por las posturas de conservación ambientalista, el rescate de los usos y costumbres de los pueblos. Es así que es factible practicarlo en diferentes lugares, en tal sentido Ancash es un lugar que cuenta con una geográfica muy particular, porque se encuentra en una cadena de montañas donde se exponen los Callejones de Huaylas y Conchucos, además que se encuentra el punto más alto del Perú que es el Huascarán, se ubican provincias muy concurridas por los turistas como son Yungay, Carhuaz, Huaraz y Huari, este último fue el centro hegemónico de la primera gran cultura del Perú que fue Chavín (Agencia Peruana de noticias Andina, 2017). A su vez, en estos lugares se rescata la artesanía con trabajos en piedra, arcilla, madera, hueso y vidrio, que llaman la atención a los visitantes.

La investigación se realizó en el distrito de Chacas, la actividad económica más importante es la agricultura, sin embargo, aún no implementan una mejora respecto a la actividad turística, inventarios, promoción y desarrollo sostenible. El pueblo cuenta con un santuario conocido como Mama Ashu, sin embargo, los servicios complementarios a esta visita aún son escasos e incipientes. Es por ello que es importante plantear una propuesta de fomento turístico 
que permita generar oportunidades de empleo, sostenibilidad laboral, mejoras en los servicios al turista, preservación de la identidad, la conservación de las tradiciones y su naturaleza.

En tal sentido, se revisó la Teoría del turismo rural, donde se establece la clasificación de las diversas actividades como son los talleres artesanales, agroturismo, talleres de gastronomía, aprendizaje de idiomas y dialectos, medicina tradicional, eco arqueología, fotografía rural y etnoturismo que permitan el desarrollo del turismo rural con el propósito de valorar la cultura y la identidad de los pobladores. Por otra parte, la teoría del espacio turístico de Boullon, considera como elementos del espacio turístico a las zonas turísticas, complejos, áreas, redes, unidades y las estadías como destinos turísticos para consolidarse como atractivos de visita (Panosso y Lohmann, 2012).

Del Valle (2015) analizó la situación actual del turismo rural en España, con el fin de crear una oferta de alojamiento que está relacionado al espacio rural a que llegó, mientras que. Patiño (2016) formuló una estrategia de desarrollo local para implementar mejores servicios turísticos en qué consistió. A nivel nacional, Hoyos (2016) sostuvo en su investigación un plan y acciones estratégicas para mejorar el estilo de vida de los pobladores de un distrito por medio del impulso del turismo rural. Finalmente, Alegría (2017) determinó la incidencia del turismo rural comunitario en la mejora de la calidad de vida de una comunidad campesina, identificando los factores relevantes para lograr dicha mejora socio-económica.

Debemos entender que el turismo rural se define como el conjunto de actividades realizadas en áreas rurales, ligadas al turismo moderno que conllevan al logro de metas de desarrollo sostenible para la población local, a través del uso adecuado de los recursos naturales, culturales, sociales y físicos que se consolidan como atractivos turísticos. En la práctica el turismo rural trabaja con la población local (planificación y desarrollo), analizan el desplazamiento y conocimiento adecuado de los atractivos turísticos de la zona, tanto en equipamiento e infraestructura (Mincetur, 2018; Solsona, 2006). Por ende, el turista está en contacto con la naturaleza, cubren sus expectativas, sensaciones y motivaciones que los lugares tradicionales turísticos no ofrecen. Sin embargo, existen dificultades para la práctica como son la educación de los pobladores, una adecuada formación académica en base al turismo, emigración de pobladores, falta de inversión, déficit de los servicios básicos, mejora o reestructuración de rutas turísticas, etc.

Por ende, para se consideró como sub categorías ejes de este estudio las siguientes:

La identidad cultural, definida como el sentimiento de pertenencia y mantenimiento de las costumbres, valores, creencias que se conservan de generación en generación; permitiendo que el individuo autovalore su pasado, presente y futuro y se comprometa históricamente con su entorno social (Molano, 2016; Grimaldo, 2016).

El recurso turístico, se define como el conjunto de bienes naturales, culturales, humanos y socioculturales. Dentro de otra clasificación también se pueden manifestar los recursos tangibles e intangibles. El recurso turístico despierta el interés y la motivación para la realización de desplazamientos turísticos en una determinada zona de atracción (Navarro, 2015). 
La planta turística, son los elementos que conforman el servicio y producto turístico en una determinada zona o destino, como por ejemplo restaurantes, hoteles, aeropuertos, carreteras, terrapuertos, etc. Es preciso indicar que la planta turística se desarrolla teniendo ubicación, condiciones y características de los atractivos turísticos en su zona de influencia; manifestándose como núcleos receptores de los turistas en base a un buen equipamiento, instalación y calidad de servicio ante la demanda de los visitantes (Quesada, 2000).

El objetivo general de la investigación fue: Diseñar un plan de potencialización del turismo rural en el distrito de Chacas, departamento de Ancash, Perú; mientras que los objetivos específicos fueron: Determinar el turismo rural como alternativa de desarrollo sostenible en las zonas no urbanas del Perú; diagnosticar el contexto actual del distrito de Chacas, departamento de Ancash, Perú, en base a un estudio cuanti-cualitativo.

\section{Materiales y Métodos}

El estudio se ampara en un enfoque mixto con una interpretación cuantitativa y análisis cualitativo del contexto en estudio. En función al sintagma holístico, el tipo de investigación es proyectiva, basada en una propuesta luego de un diagnóstico profundo (Hurtado, 2000). La categoría en estudio fue turismo rural y las sub categorías: identidad cultural, recurso turístico y planta turística. Se trabajó con una muestra cuantitativa de 51 pobladores del distrito de Chacas, la información que se obtuvo fue a través de encuestas tipo Likert con validez y confiabilidad. Asimismo, se realizó el análisis cualitativo a partir de entrevistas a 3 expertos en turismo que conocen la zona en estudio. Para el procesamiento de información, resultados estadísticos y triangulación se utilizó en programa SPSS y el Atlas ti.

\section{Resultados}

En función a la aplicación y procesamiento de datos cuantitativos se destaca la siguiente información con respecto a la identidad cultural de los pobladores del distrito en estudio, el 90,2\% indica que se identifica con su lugar de origen y el 9,8\% manifiesta poca identidad con su tierra natal. Con relación a sus costumbres, el 76,5 \% indican que parte de ellas son sus fiestas patronales, el 15,7\% lo reflejan en sus danzas típicas y un 7,8\% indican que una de sus costumbres ancestrales son las corridas de toros. Referente al conocimiento y conservación de los recursos turísticos el 70,6\% del total de encuestados conocen de manera regular los recursos de su zona y que los mismos se encuentran mediadamente conservados. Con respecto a las actividades relacionadas con el turismo rural, el $62,7 \%$ de los encuestados la relacionan con talleres de artesanía, un 19,6\% consideran que el turismo rural es compartir su estilo de vida, el $11,8 \%$ lo relaciona con el agroturismo, el 3,2\% con la caza y pesca y el $2 \%$ con la gastronomía de la zona.

La subcategoría planta turística se describió en base a los establecimientos con lo que cuenta el distrito de Chacas, determinándose que el $43,1 \%$ son restaurantes, el 11,8\% albergues, el 35, 3\% hoteles y el 9,8\% son casas rurales. Finalmente, desde la descripción cuantitativa, con respecto a la señalización de atractivos turísticos solo un 9,8\% indican que existe una buena señalización, y un 64,7\% manifiestan que solo algunos atractivos turísticos tienen señalización, mientras que para el 25,5\% no existe señalización en las zonas turísticas. 
Asimismo, en las entrevistas realizadas a los expertos respecto: ¿Cuál es el evento cultural más importante en Chacas? ¿Cuándo y cómo se celebra?, los tres entrevistados coinciden en que el evento cultural más importante de Chacas es la fiesta de 15 de agosto de cada año, en honor a la Virgen de Asunción (Mama Ashu). Consiste en la presentación de danzas costumbristas como: Huanquillas, Anti runa y Carrera de cintas, a la vez se desarrolla la corrida de toros, acompañada de la banda de músicos y con juegos artificiales. En el día central se realiza una misa a cargo de varios párrocos que vienen de diferentes provincias de Ancash, cabe precisar que las actividades se realizan, así como de Italia, por la presencia de colonos en la zona. No obstante, se realiza homenajes en todo el año a diversos santos como la procesión del Señor de los Milagros y la fiesta de San Martin de Porres cada 18 de octubre y 5 de noviembre respectivamente.

Con respecto a la planta turística se hizo las siguientes preguntas: ¿En general como considera los servicios de establecimientos turísticos en Chacas, ¿Qué opina usted sobre la accesibilidad a Chacas y en qué estado se encuentra?, los entrevistados afirman que no existe una buena planificación y organización en los restaurantes, porque no tienen conocimiento de las temporadas altas y bajas del turismo, por ende es importante conocer y hacer un estudio sobre las temporalidades de afluencia de turistas de esta manera prestar un servicio de calidad al cliente. En cuanto a la accesibilidad consideran que gracias a la pista asfaltada de Carhuaz a Chacas el acceso es más rápido, pero las móviles tienen tarifas muy altas y no existen agencias de viaje perennes para el distrito y sus alrededores. En definitiva, los restaurantes son el punto débil del conjunto de elementos que conforman la planta turística, perjudicando la difusión gastronómica de la zona.

Para el análisis de los recursos turísticos se analizó las respuestas de las siguientes preguntas: ¿Cuántos recursos y atractivos turísticos conocen en Chacas? ¿Cuáles son? ¿Qué actividades turísticas podrían realizarse, en el espacio rural de Chacas? ¿Cuáles de los aspectos culturales, de tradiciones y costumbres cree usted que podrían ser de interés para los visitantes?, evidenciando que existen bastantes recursos turísticos, sobre todo en la zona rural como laguna Esmeralda, Patarcocha, Yana Raju, Laguna Belaunde, los cuales se encuentran en diferentes caseríos de Chacas, sin embargo, estos no están puestos en valor, no existe una oficina de información para dar detalles acerca de la existencia de dichos recursos turísticos.

Uno de los atractivos turísticos del distrito, es el taller de artesanía Don Bosco impulsado por el padre Hugo de Censi (lamentándose hace poco su desaparición), donde se realizan hermosos trabajos de tallados en madera, arcilla y vitrales, con bastante originalidad. Complemento a esta actividad se encuentran la cosecha de papa, trigo, oca. 


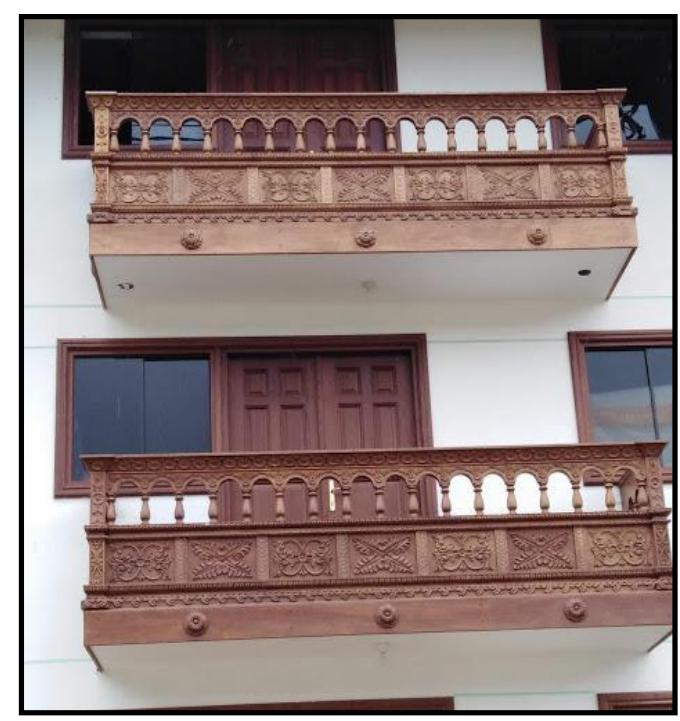

Figura 1. Tallado en maderas. Foto: Malvas, S.

La práctica del turismo rural en Chacas Ancash ha tomado mucho impulso, pero aún su fomento y mejora es incipiente, lo cual queda demostrado en el estudio cuantitativo y cualitativo. Ante ello la necesidad de una propuesta de mejora.

\section{Potencialización del turismo rural}

El turismo rural se circunscribe a espacios no urbanizados donde prevalece el estado natural y cultural del pueblo, basándose en la identidad y sentimiento de pertenencia del poblador (Ibañez y Cabrera, 2011), por ello ofrece oportunidades laborales a los lugareños, lo cual permite mejorar su calidad de vida, para ello se plantean tres objetivos estratégicos:

Objetivo 1: Implementar el desarrollo del turismo rural fomentando la participación activa de los pobladores locales de diversas condiciones (edad, sexo, grado de instrucción).

\section{Actividades:}

- Conformación de un centro informativo en el distrito que permita brindar datos y descripciones de los atractivos turísticos. Fomento de un circuito turístico zonal y distrital, incluyendo actividades innovadoras que complementen al mismo como el trekking y hiking.

- Poner en funcionamiento del portal web que permita vincular los atractivos turísticos de Chacas con las redes sociales.

Objetivo 2: Fortalecer la identidad cultural con la participación directa y activa de la comunidad en las manifestaciones culturales de la zona.

Actividades:

- Potencializar el taller de artesanía de Don Bosco, difundiendo el esplendor de su arte que se crea en base a madera, vidrio y arcilla.

- Involucrar a la comunidad de todas las edades para que participen en las fiestas patronales, danzas costumbristas y representaciones pintorescas del pueblo. 
- Fomentar en los menores de edad, el amor a sus costumbres, principalmente las danzas y bailes a través de concursos infantiles de danzas típicas del lugar.

Objetivo 3: Fomentar fuentes de trabajo para los pobladores de la zona en base a este turismo alternativo.

Actividades:

- Explicar las ventajas económicas y motivar a los pobladores de la zona a la práctica de alojamiento rural.

- Fomentar la participación de los habitantes de la zona en la actividad turística, como personal tour (que pueden ser estudiantes, de nivel básico bien preparados y/o con estudios de turismo), colaborador en los campamentos, excursiones, expositor y guía turístico.

\section{Conclusiones}

El turismo rural como alternativa de desarrollo sostenible, permite un impacto positivo en la comunidad no urbana, mejora la calidad de vida de los pobladores, incrementa las fuentes de trabajo, permite conservar el patrimonio natural y cultural con la participación activa de todos los lugareños, además que fomenta el amor al lugar de origen y costumbres.

Evidenciándose que, en el distrito de Chacas ubicado en Ancash, existe poco conocimiento del patrimonio cultural y natural, no se realizó un inventario turístico, tampoco existen medios de difusión e información de los atractivos y los circuitos turísticos, por lo tanto, no existe una adecuada conformación, distribución y uso de la planta turística.

Finalmente, se propone un conjunto de actividades, de los cuales destacan el fortalecimiento de la identidad cultural, difusión de los atractivos turísticos zonales, el fomento de fuentes de empleo y la participación activa del poblador.

\section{Bibliografía}

Agencia peruana de noticias Andina (09 de junio del 2018) Ancash: Nevados, Chavín de Huántar y turismo rural comunitario. Recuperado de https://andina.pe/agencia/noticiaancashnevados-chavin-huantar-y-turismo-rural-comunitario-vamos-pal-norte-670309.aspx

Alegría, G. (2017) El turismo rural comunitario y su incidencia en el nivel de vida de la comunidad campesina de Honqopampa - Carhuaz. (Tesis de maestría en políticas sociales). Huaraz: Universidad Nacional San Antúnez de Mayolo.

Del Valle, E. (2015). Turismo Rural en España. Análisis de la evolución del modelo de desarrollo y perspectivas futuras. (Tesis de doctorado). Ourense: Universidad de Vigo.

Diario El Comercio (2016) Promperu: Arequipa, Puno y Cusco aprovechan el turismo rural. Recuperado de: https://elcomercio.pe/economia/negocios/promperu-arequipa-puno-cuscoaprovechan-turismo-rural-271552 extraído el día 28 de agosto de 2018. 
Ibáñez R. y Cabrera C. (2011). Teoría General de turismo: Un enfoque global y nacional. México. Universidad Autónoma de Baja California Sur

Forneau, F. (1998) El turismo en espacio rural en Francia. Cuadernos de turismo, 1:41-53. http://revistas.um.es/turismo/article/view/24681Panosso, A. y Lohmann, G. (2012) Teoría del Turismo: conceptos, modelos y sistemas. México: Trillas

Grimaldo, M. (2006) Identidad y política cultural en el Perú. Lima. Universidad de San Martin de Porres. http://www.redalyc.org/articulo.oa?id=68601205

Hoyos, K. (2016). Estrategias para el desarrollo del Turismo Rural Comunitario en el distrito de Huaros provincia de Chachapoyas. (Tesis de Título de Ingeniero en Agroturismo). Lima: Universidad Federico Villarreal.

Hurtado, J. (2000). Metodología de la investigación holística. Caracas. Fundación Sipa.

MINCETUR (2018) Programa Nacional de Turismo Rural Comunitario. https://www.mincetur.gob.pe/producto-turistico/turismo-rural-comunitario/

Molano, O. (2016) La identidad cultural, uno de los detonantes del desarrollo territorial. Articulo Territorio con identidad cultural. https:// identidad-cultural-uno-de-los-detonantes-deldesarrollo-territorial

Navarro, D. (2015) Recursos Turísticos y Atractivos Turísticos: Conceptualización, clasificación y valorización. Cuadernos de Turismo; 35 335-357. DOI:10.6018/turismo.35.221641 unwto.org/

Organización Mundial de Turismo, (2008). Introducción al turismo. https://www.e-

Panosso, A. y Lohmann, G. (2012) Teoría del Turismo: conceptos, modelos y sistemas. Trillas México.

Patiño, A. (2016) Turismo rural comunitario como estrategia de desarrollo local para el municipio de Mejía (Tesis de magister en economía y gestión del turismo). Argentina: Universidad de Buenos Aires. distancia.

Quesada, R. (2000). Elementos de turismo. San José, Costa Rica: Universidad estatal a

Solsona J., (2006) El Turismo Rural en Europa. Revistas Científicas de América Latina, El Caribe, España y Portugal; 10; 25-35. http://www.redalyc.org/pdf/276/27610204.pdf

World Tourism Organization (2018). Tourism for Development. I Key Areas for action. UNWTO. Madrid. DOI: https://doi.org/10.18111/9789284419722. 